
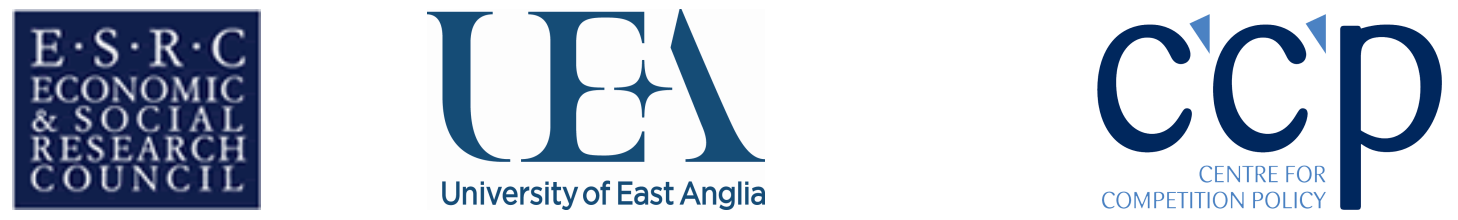

\title{
Price Transparency and Consumer Naivety in a Competitive Market
}

by

\author{
Luke Garrod \\ ESRC Centre for Competition Policy, University of East Anglia
}

\section{CCP Working Paper 07-10}

\begin{abstract}
Despite intense price competition firms obfuscate product information when it is relatively costless to reveal, contrary to neoclassical predictions. This paper considers whether firms can profitably conceal (part of) their prices for a homogeneous product when consumers differ in their ability to form expectations of market prices. The model shows that the ability to conceal prices but still attract naïve consumers dampens competition and allows prices to be set above marginal cost. This suggests that the European Commission was correct to pass regulations that require airlines to set prices inclusive of taxes, fees and charges, because alternative policies of educating a proportion of naïve consumers to become sophisticated or assisting consumers to search the market more effectively could increase prices in some situations.
\end{abstract}

April 2008 (original version: May 2007)

JEL Classification Codes: L13, D18, D83

Keywords: bounded rationality, obfuscation, price transparency

\section{Acknowledgements:}

I am thankful for suggestions made by Bruce Lyons and Chris Wilson. The support of the Economic and Social Research Council is also gratefully acknowledged.

\section{Contact details:}

Luke Garrod, ESRC Centre for Competition Policy, University of East Anglia, Norwich, Norfolk, NR4 7TJ, UK

l.garrod@uea.ac.uk 


\section{Introduction}

There is a growing literature that believes firms and consumers are likely to differ in their ability to understand a market in which they interact. ${ }^{1}$ Competing firms have an incentive to maximise profits as otherwise they may be forced to exit the market by other profit-maximising firms; whereas consumers face no such pressures. Similarly, the size of the gain from a precise maximisation will typically be larger for firms. Consequently, firms are likely to analyse the market more vigorously than consumers, who perhaps only interact with firms intermittently which may limit their understanding further. Thus, firms may have an incentive to exploit any consumer inaccuracy and attempt to increase errors by obfuscating product information to limit price competition.

Milgrom (1981) predicted that competing firms will fully inform consumers of product information if it is feasible and costless. The intuition is that the firm offering the best terms will disclose its product information and consumers realise that any concealment is likely to be unfavourable. ${ }^{2}$ However, this prediction is based upon the assumption that consumers have the cognitive ability to infer that they should avoid firms with hidden information, which raises the question: do firms have an incentive to disclose information if some consumers naively visit firms with hidden information? This paper considers whether firms can profitably conceal (part of) their prices when consumers differ in their ability to form expectations of market prices.

A second motivation stems from recent behaviour within the European shorthaul airline market where, despite cut-throat competition, firms consistently obscured their market prices on the internet by separating them into (observable) base prices and (hidden) taxes, fees and charges (TFCs). In particular low-cost carriers on occasions advertised base prices below $£ 1$. Figure 1 provides a typical example of a low-cost carrier's advertisement.

\footnotetext{
${ }^{1}$ See Ellison (2005) for an in-depth review.

${ }^{2}$ In contrast, Cheong and Kim (2004) show that firms may not disclose quality information in equilibrium if disclosure is costly.
} 
Figure 1: An example of a low-cost carrier's advertisement for a 'free' airline ticket

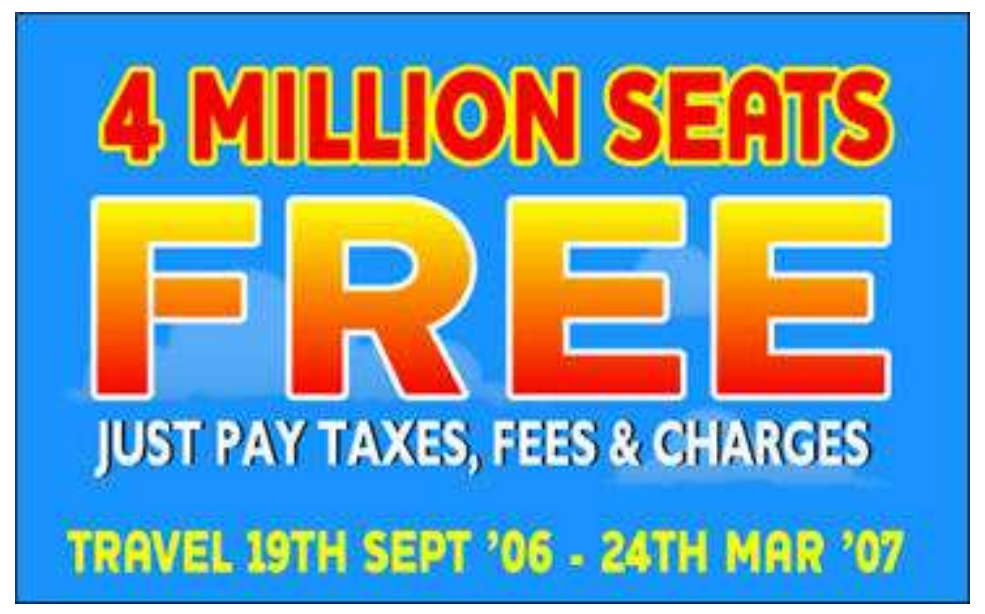

The Air Transport Users Council (AUC) believed that airlines used low base prices on their websites to attract consumers who were unaware that advertised prices did not include firm-specific TFCs until they were set on purchasing the flights (AUC report 2005). Due to this behaviour, last year the European Commission passed regulations that require airlines to quote prices inclusive of TFCs to prevent advertisements misleading consumers. ${ }^{3}$ This paper allows us to analyse the effect on prices and consumer welfare of such a policy.

The model can also be used to describe other situations where firms obfuscate price information. For example, it is a common practice for internet retailers to divide a product's total price into the 'price' for the good and a shipping and handling fee. ${ }^{4}$ Travel agents also commonly include taxes and (sometimes unavoidable) add-ons in a holiday's total price after consumers have observed a lower basic price and received information about their potential holiday.

\footnotetext{
${ }^{3}$ See European Commission Press Release, More competition and better quality: European Commission wants to strengthen the Single Market for Aviation, 18 July 2006, available at: http://europa.eu/index_en.htm.

${ }^{4}$ In some cases shipping and handling may be an 'add-on' (see Gabaix and Laibson, 2006). But in many cases it is a necessity and consumers are unable to substitute away from the supplying firm, so it could be seen as part of the purchased good.
} 
A theoretical model is developed where firms can choose a transparent or non-transparent pricing strategy. In the former, a firm's price is common knowledge; in the latter, a firm sets an observable price (which is common knowledge) and a hidden fee, which consumers can discover at some cost. If (all) consumers form correct expectations they fear the worst from nontransparent firms, so visit the firm with the lowest transparent price. As such, firms select transparent strategies and set marginal cost pricing. However, within the model there are a proportion of sophisticates who form correct expectations, and a proportion of consumers who are unaware of firms' hidden fees and naively visit the firm with the lowest observable price. Nevertheless, naïve consumers realise their mistake and form correct expectations if they observe a positive hidden fee and can switch at some cost.

The model finds that market prices are always greater than marginal cost, because for any positive proportion of naïve consumers some firms obfuscate their prices to attract naïve consumers. At best, when firms have constant marginal costs and unconstrained capacities, there is only one firm that sets a transparent strategy. Crucially, optimal pricing depends upon the transparent firm's incentive to attract naïve consumers after they have been fooled by low observable prices and consider switching. This means competition is most intense when the proportions of sophisticated and naïve consumers are relatively even, which suggests any policies that aim to increase the proportion of sophisticates may actually harm both types of consumers.

Furthermore, firms have no incentive to set transparent prices (to the detriment of consumers) unless effort cost is above some threshold. However, if there is a transparent firm, market prices increase with the naïve consumers' effort cost of switching to the transparent firm. Although effort cost is assumed to be exogenous within the model, this suggests that there is the potential for two forms of obfuscation occurring. Firstly, non-transparent firms fool naïve consumers with low observable prices and high hidden fees; secondly, a transparent firm has an incentive to increase the complexity of the switching task for naïve consumers to dampen competition. 
The paper is structured as follows. The next section briefly discusses related papers within the search, obfuscation and bounded rationality literatures. Section 3 presents the model and section 4 provides the equilibrium analysis. The model's comparative static results are discussed in section 5 and section 6 provides some policy implications. Section 7 concludes.

\section{Related Literature}

Empirical studies have provided evidence that obfuscation is widespread in several markets. Surprisingly, much of the evidence of information suppression is prominent in internet retailing, which in its advent promised more intense price competition due to the consumers' ability to quickly search markets to find the cheapest firm. Ellison and Ellison (2004) suggest that firms have adapted to increases in price competition by introducing obfuscation strategies that prevent consumers from searching a market as effectively as they would otherwise. For instance, they find evidence that when competition is intensified by a price search engine internet retailers create multiple versions of products that complicate consumers' understanding of a product's quality to the extent that consumers find it difficult to understand what is on offer, and which products should be compared.

The recent theoretical literature has shown that obfuscation can be profitable in equilibrium despite competitive constraints. Ellison (2005) suggests that the simplest way to consider the impact of obfuscation strategies is to regard them as simply increasing search costs in models such as Stahl (1989). Intuitively, the search costs are considered as a consumer's cognitive cost of understanding information, as discussed in Salop and Stiglitz (1977), rather than the traditional interpretation of a consumer's effort of gathering information.

However, recent theoretical models of obfuscation have been primarily considered in papers that include (at least some proportion of) consumers 
who have cognitive limitations. For instance, Gabaix and Laibson (2006) consider a market where firms can obfuscate their prices for a complementary add-on of an original good; for example, consider a hotel room as the original good and refreshments in the room's mini bar as the add-on. They show that when there are a sufficient proportion of consumers that (myopically) do not consider the add-on when purchasing the original good, firms find it profitable to hide the add-on's price. Firms exploit myopic consumers by attracting them with low original prices but set high add-on prices. However, sophisticated consumers also exploit firms by taking advantage of low original prices but substitute away from high priced add-ons. Interestingly, it is not profitable for firms to deviate from the equilibrium by revealing its add-on price and warning consumers of rivals' obfuscation strategies as it only reduces the proportion of consumers purchasing the add-ons.

Spiegler (2006a) analyses a situation where consumers use heuristics to overcome their inability to understand a product's multiple dimensions: they pick one dimension and select the product that from their analysis is best. In this model firms respond to an increase in the number of competitors by increasing the complexity of their product which can be detrimental to consumers. However, in a similar model Gaudeul and Sugden (2007) show that competitive forces are sufficient to unravel firms' incentive to complicate consumers' tasks when consumers have a limited cognitive ability of comparing products.

Wilson and Waddams Price (2007) provide evidence that some consumers in the electricity market actually switched to suppliers with higher tariffs, even though they stated price as the only reason for switching. They argue that consumer errors are likely to be due to the difficulty of comparing firms' complex non-linear tariffs.

Opposed to obfuscation strategies, there are several competing hypotheses to explain why firms divide price into different components. Bertini and Wathieu (2006) argue that partitioned prices affect consumers who use a psychological mechanism to calculate their perceived product valuation, because it 
increases the amount of product attributes that are processed at the time of valuation, which may enable consumers to estimate their valuation better or lead to over-estimation. Alternatively, Thaler (1985) argues that consumers who use a type of mental accounting based on prospect theory (Kahneman and Tversky, 1979) would be more willing to purchase a product with an allinclusive price compared to a partitioned price, as multiple losses are perceived greater than an equivalent single loss.

Hossain and Morgan (2006) conduct a field experiment on auction websites to discover whether consumers are affected by obfuscation strategies or mental accounting when faced with partitioned prices. They use the common practice in internet shopping of separating a product's total price into a shipping fee and a 'price' for the good to subtly change how the total amount paid is framed. They show a seller's revenue for identical products is significantly lower when shipping fees are not prominently displayed, which (perhaps paradoxically) suggests obfuscation is not a profitable strategy. However, there is some evidence that consumers use mental accounting because significantly higher revenue is received when the level of the hidden shipping fee is increased, holding the total amount paid constant; but this effect vanishes when the fee is not hidden.

However, firms may partition prices to influence their rival firms' behaviour, by including surcharges, such as airlines' fuel supplements, to facilitate higher supracompetitive prices during a temporary cost shock (Garrod, 2006). Møllgaard and Overgaard (2005) suggest price transparency has an ambiguous effect upon tacit collusion as decreased transparency reduces the profitability of a deviation but also reduces firms' ability to punish, because consumers are more likely to observe price reductions and change supplier.

As we have seen in some papers discussed above, it is now not unusual for theoretical models to include consumers with cognitive limitations or behavioural biases. Other papers that consider the implications of consumers' cognitive limitations on profit-maximising firms' behaviour include DellaVigna and Malmendier (2004) and Eliaz and Spiegler (2006) who consider the 
impact of consumers' biased beliefs concerning future tastes; Chen et al (2002) and Piccione and Rubinstein (2003) analyse firms' behaviour when consumers differ in their ability to remember past prices; and Spiegler (2006b) shows how a market for charlatans can exist when agents use a rule-of-thumb to estimate a product's quality. Similarly, Heidhues and Koszegi (2006) and Rotemberg (2005) consider how the behavioural biases of loss aversion and preferences for fairness affect competition, respectively.

\section{The Model}

Consider a market where $n$ firms compete on price in a one-shot game to sell a homogeneous product to a unit mass of consumers. Firms select a single market price, $p_{i}^{m}$, which consumers pay when purchasing from firm $\mathrm{i}=\{1, \cdots, n\}$. However, firms can make their market prices common knowledge or not by setting a transparent or non-transparent pricing strategy. For instance, a non-transparent firm can include a hidden fee, $\hat{p}_{i}$, with a (common knowledge) observable price, $p_{i}$, such that $p_{i}^{m}=p_{i}+\hat{p}_{i}$; whereas a transparent firm does not set a hidden fee. Formally, firm i's price is

$$
p_{i}^{m}=p_{i}+I_{\hat{n}}(i) \hat{p}_{i}
$$

where

$$
I_{\hat{n}}(i)= \begin{cases}0 & \text { if } i \notin N \\ 1 & \text { if } i \in N\end{cases}
$$

and $\hat{n}$ is a subset of firms that set non-transparent prices. All firms have constant marginal costs, given by $c>0$ and so the profit function of firm $\mathrm{i}$ is $\pi_{i}=\left(p_{i}+I_{N}(i) \hat{p}_{i}-c\right) q_{i}$, where $q_{i}$ is the quantity sold by firm $\mathrm{i}$.

Consumers know which firms have transparent pricing strategies ${ }^{5}$. Within the population of consumers there is a subset of sophisticates, $\alpha \in[0,1)$, who use

\footnotetext{
${ }^{5}$ In the airline industry firms commonly avoided the Advertising Standard Authority's transparency rules by stating the observable price was exclusive of TFCs (which is evident in Figure 1). Similarly, other airlines would announce that their price was inclusive of TFCs. Some firms would also go as far as to warn consumers of being misled by low observable prices.
} 
this information to form beliefs of firms' market prices when deciding which firm to buy from. However, there are a proportion $(1-\alpha)$ of naïve consumers who only consider observable prices when selecting a firm. Within the proportion of naïve consumers a subset $\lambda$ become sophisticated if a firm warns them to consider hidden fees. All consumers have a unit demand and value the homogeneous good at $v>c$. Thus, each trade has a surplus $v^{*}=v-c$ which will be divided between the consumer and the supplying firm. The timing of the game is as follows:

\section{Stage 1:}

- Firms can make prices transparent or not. Define $\mu_{i} \in\{T, N\}$ as firm i's binary decision to set a transparent $(T)$ or non-transparent pricing strategy $(N)$.

- Firms also have a binary choice to warn consumers of hidden fees which is defined as $\omega_{i} \in\{$ warn, not warn $\}$.

\section{Stage 2:}

- Firms set prices $p_{i}$ and, if necessary, $\hat{p}_{i}$ simultaneously to maximise expected profit given the vectors $M=\left\{\mu_{1}, \cdots, \mu_{n}\right\}$ and $W=\left\{\omega_{1}, \cdots, \omega_{n}\right\}$ at no cost.

- Consumers are informed of firms' observable prices, $P^{O}=\left\{p_{1}, \cdots, p_{n}\right\}$, but are unsure about (some) market prices, $P^{m}=\left\{p_{1}^{m}, \cdots, p_{n}^{m}\right\}$. Sophisticated consumers $(\alpha)$ form Bayesian beliefs about market prices, given by $\tilde{P}^{m}$, whereas naïve consumers $(1-\alpha)$ do not consider hidden fees, so select a firm by $P^{O}$.

- If there is at least one firm that sets $\omega_{i}=\{$ warn $\}$ a fraction $\lambda \in(0,1)$ of naïve consumers become sophisticated. 
- Consumers choose a firm (denoted $x$ ) given their beliefs and observe $p_{x}^{m}$. If $\hat{p}_{x}>0$, (naïve) consumers form Bayesian beliefs about market prices, $\tilde{P}^{m}$. Consumers can purchase from firm $x$ or search non-transparent firms at effort $e>0$ per firm, or switch to a transparent firm, if it exists, also at effort $e{ }^{6}$

The form of bounded rationality within the model is therefore only a minor departure from full rationality. There is an initial proportion of naive consumers, but all naïve consumers become sophisticated if they are misled. Moreover, a further proportion becomes sophisticated before they can be misled, if any firm warns consumers of hidden fees. Therefore, the closer $\alpha$ and $\lambda$ (if a firm warns) are to one and the lower is $e$, the less departure there is from standard full rationality.

\subsection{Details of the Game}

This section provides further explanation of the assumptions of behaviour and, to motivate the model, it discusses how it relates to consumers' behaviour on airlines' websites as discussed by the AUC report (2005).

\section{Stage 1:}

The strategy of some airlines advertising very competitive base prices but charging much more by adding their TFCs to the advertised base price towards the end of the booking, as in Figure 1, is modelled in stage 1 where firms can vary the transparency of their prices. It is assumed to take place before firms set prices as firms' transparency decisions may be a mediumterm strategy compared to short-term pricing strategies. For instance, if an airline changes its transparency strategy it may involve a time consuming website redesign of the firm's booking system, whereas changing prices can be done on a day-to-day basis. Thus, it is likely that firms will know their rivals' strategies before setting prices.

\footnotetext{
${ }^{6}$ The assumption of same effort costs does not affect the analysis because in equilibrium only naïve consumers' switching cost to transparent firms matters (see section 4).
} 
In stage 1 firms also have the ability to warn consumers of their rivals' tactics, by advertising the fact that consumers should take into account firms' ability to add hidden fees on to low base prices. The proportion of naïve consumers warned is assumed to be fixed and less than unity to allow for the case that some may either not observe the information or may have cognitive limitations that prevent them from forming the correct expectations about hidden fees. ${ }^{7}$ Therefore, providing information about hidden fees increases the proportion of sophisticated consumers within the market. In what follows define $\alpha^{\prime}$ as the number of sophisticates and warned naïve consumers within the market which is $\alpha^{\prime}=\alpha+\lambda(1-\alpha)$ if at least one firm sets $\omega_{i}=\{$ warn $\}$ but $\alpha^{\prime}=\alpha$ otherwise.

\title{
Stage 2:
}

Consumers enter the market and have to search for hidden fees but observable prices are common knowledge. In the European airline industry firms commonly advertised only their base prices on their websites, but as the AUC report (2005) explains:

\begin{abstract}
... consumers are often not aware of the total inclusive price until they are a long way into the booking process, when they are likely to have chosen their flights and are just about to confirm the booking. At this stage, they might not wish to give up and look elsewhere. [AUC Report 2005, p6]
\end{abstract}

The search cost to find hidden fees can be seen as consumers visiting each airline's webpage at no cost, which informs them of firms' base prices only. To observe TFCs consumers must choose flights and input their details before realising the firm's market price, which is likely to be more time consuming than simply visiting firms' websites. Alternatively, effort could be considered as a consumer's 'fear' of a price rise if they postpone their purchase to search further, given that they understand that airlines have a set number of seats at certain prices.

\footnotetext{
${ }^{7}$ Since not all naïve consumers are warned, it allows us to focus on the case when there is a positive proportion of naïve consumers in equilibrium. If there are no naïve consumers, firms set transparent prices at marginal cost.
} 
It is assumed that search is without recall; that is, it is as expensive for a consumer to visit a firm that has been searched as it is a firm that has not. For example, if an airline's market price is common knowledge consumers are still required to select a flight and input their details which will be just as time consuming as searching for hidden fees where the same process applies. Therefore, the effort cost in the model can be seen as a cost of searching a non-transparent firm or a cost of switching to a transparent firm. With no loss of generality, it is assumed consumers find their first hidden fee without cost, but they experience a cost for each firm they switch to or search after that.

Sophisticates can be seen as consumers who command an adequate understanding of the market. They have no cognitive limitations to prevent them from forming correct beliefs about firms' hidden fees, so $E\left(\hat{p}_{i}\right)=\hat{p}_{i}$ and $\tilde{P}^{m}=P^{m}$. The optimal search strategy for sophisticates maximises their net expected trading surplus. Sophisticates realise that non-transparent firms have an incentive to set low observable prices to attract naïve consumers but charge high hidden fees as consumers have an effort cost to switch to other firms. ${ }^{8}$ Thus, they select the firm with the lowest transparent price, which they expect to be the lowest market price, $\min \left\{P^{m}\right\}$. They purchase the product if its price is less than or equal to their valuation. If there are $m>1$ firms with $\min \left\{P^{m}\right\}$, it is assumed sophisticates randomly select between these $m$ firms. If there are no transparent firms, sophisticates optimally select a firm at random and search the market further if $p_{x}^{m}>E\left(p_{i}^{m}\right)+e \forall \mathrm{i}$.

Naïve consumers are likely to be consumers who have little or no experience of the market, so do not fully understand firms' pricing strategies. The AUC report (2005) was particularly concerned by firms' ability to advertise low observable prices as some consumers may not have the cognitive capacity to form correct beliefs about firms' hidden fees. For example:

... passengers might not be aware that different airlines can charge different levels of TFC, even on identical routes ... because they

\footnotetext{
${ }^{8}$ It is proved in proposition 1 that non-transparent firms set higher market prices.
} 
assume that TFCs are imposed by a third party and are therefore standard across all airlines operating one route. [AUC Report 2005, p6]

Naïve consumers as modelled in this paper do not consider hidden fees. This type of consumer can be considered the same as described in the quotation above, because for a homogeneous product both types of behaviour would only be price sensitive by the observable price, as opposed to the expected total price. Similarly, they may be seen as consumers who use observable prices as a simple 'rule of thumb' to predict market prices as cognitive limitations prevent them from correctly predicting expected hidden fees.

If naïve consumers are fooled by non-transparent strategies they instantly become sophisticated to form correct beliefs $\left(E\left(\hat{p}_{i}\right)=\hat{p}_{i}\right.$ and $\left.\tilde{P}^{m}=P^{m}\right)$ when they observe a positive hidden fee. This can be seen as a learning effect as consumers that initially believe all airlines' TFCs are the same are more likely to reconsider their beliefs after they have observed that their chosen firm has implemented a firm-specific surcharge. Consumers with cognitive limitations may simply change their beliefs to (correctly) believe that firms with hidden fees are more expensive. Of course, it is possible that consumers are still naïve after having at least one experience in the market. However, in this model it is assumed all consumers become sophisticated because it provides firms with the smallest incentive to set a non-transparent strategy. This also has the benefit of simplifying the analysis.

The search strategy for naïve consumers is complicated by the possibility of each consumer initially visiting a firm with a low observable price and then wishing to switch to a transparent firm thereafter, if they have made a mistake. Therefore, naïve consumers (possibly mistakenly) select the firm with the lowest observable price, $\min \left\{P^{O}\right\}$. If there are $\hat{m}>1$ firms with $\min \left\{P^{O}\right\}$, it is assumed naïve consumers randomly select between these $\hat{m}$ firms. If $\hat{p}_{x}=0$, they observe no hidden fee and do not become sophisticated, so purchase the product under the belief that this is the cheapest firm in the market. If 
$\hat{p}_{x}>0$, consumers become sophisticated and realise that non-transparent firms charge higher market prices and will optimally switch to the firm with the lowest transparent price if $\min \left\{\tilde{P}^{m}\right\}+e<p_{x}^{m}$, again randomly selecting a firm if $m>1$; otherwise they purchase from their original firm, if its price is less than consumers' valuations.

\section{Equilibrium}

Firms are assumed to be risk neutral and set prices such that the optimal pricing strategies are subgame perfect. In the event that firms play mixed strategies in stage 2 (in equilibrium this occurs when there is only one transparent firm, defined as 1) firm 1's probability distribution of prices is $F_{1}\left(p_{i}^{m}-e\right) \forall i \neq 1$ with price support $\left[\underline{p}, p^{*}\right)$. If all remaining firms set $\mu_{i}=\{N\}$

their probability distributions of prices are given by $F_{i}\left(p_{1}+e\right)$ with support $\left[p^{*}, \bar{p}\right]$. Since $F_{1}\left(p_{i}^{m}-e\right)$ and $F_{i}\left(p_{1}+e\right)$ are the probabilities that $p_{1}<p_{i}^{m}-e$ and $p_{i}^{m}<p_{1}+e$, respectively, it follows that $F_{i}\left(p_{1}+e\right)=1-F_{1}\left(p_{i}^{m}-e\right)$. Proposition 1 establishes that it is always profitable for some firms to obfuscate their prices for any $\alpha \in[0,1)$ and prices will be greater than marginal cost.

\section{Proposition 1 Let}

$$
\underline{\alpha} \equiv \frac{v^{*}}{(1-\lambda)\left(v^{*}+e n\right)} \quad \bar{\alpha} \equiv 1-\frac{e}{(1-\lambda) v^{*}} \quad \alpha^{*} \equiv \frac{1-\lambda n}{n(1-\lambda)} \quad \text { and } \quad e^{*} \equiv \frac{v^{*}(n-1)}{n} .
$$

For finite $n$ and $e<e^{*}$ :

(A) if $\alpha<\underline{\alpha}$, all firms set $\mu_{i}=\{N\}, p=0$ and $\hat{p}=v$;

(B) if $\underline{\alpha}<\alpha<\bar{\alpha}$, there exists $n$ mixed strategy equilibria where firm 1 sets $\mu_{1}=\{T\}$ and remaining firms set $\mu_{i}=\{N\} \forall i \neq 1$ with distributions 


$$
F_{1}\left(\hat{p}_{i}-e\right)=1-\frac{e}{\left(p_{i}-c\right)(1-\alpha)}
$$

and

$$
F_{i}\left(p_{1}+e\right)=\frac{1}{1-\alpha}\left[1-\frac{e \alpha}{\left(p_{1}-c\right)(1-\alpha)}\right]
$$

respectively;

(C) if $\alpha>\bar{\alpha}$, there are $n$ pure strategy equilibria where firm i sets $p_{i}=0$ and $\hat{p}_{i}=v \quad \forall i \neq 1$, and firm 1 marginally undercuts by an arbitrarily small amount, $\varepsilon, p_{1}=v-\varepsilon$.

For finite $n$ and $e>e^{*}$ :

(D) if $\alpha<\alpha^{*}$, all firms set $\mu_{i}=\{N\}, p=0$ and $\hat{p}=v$;

(E) if $\alpha>\alpha^{*}$, there are $n$ pure strategy equilibria where firm $i$ sets $p_{i}=0$ and $\hat{p}_{i}=v \forall i \neq 1$, and firm 1 sets $p_{1}=v-\varepsilon$.

When $n \rightarrow \infty$,

(F) firms are indifferent between setting $\mu_{i}=\{T, N\}$.

When firm 1 sets $\mu_{1}=\{T\}$, it also sets $\omega_{1}=\{$ warn $\}$. Otherwise, firm $i$ has a weakly dominant strategy to set $\omega_{i}=\{$ not warn $\} \forall i$.

\section{Proof See Appendix A}

In common with other search models the two consumer types provide firms with different incentives. Naïve consumers provide firms with incentives to make their prices non-transparent and set low observable prices but use high hidden fees to exploit consumers' effort costs. Sophisticated consumers provide firms with an incentive to set transparent prices and undercut nontransparent firms to attract all consumers of this type. Crucially, in some situations a transparent firm may have an incentive to attract naïve consumers after they observe high hidden fees and consider switching. 
Figure 2: Illustration of equilibrium critical values for a finite number of firms

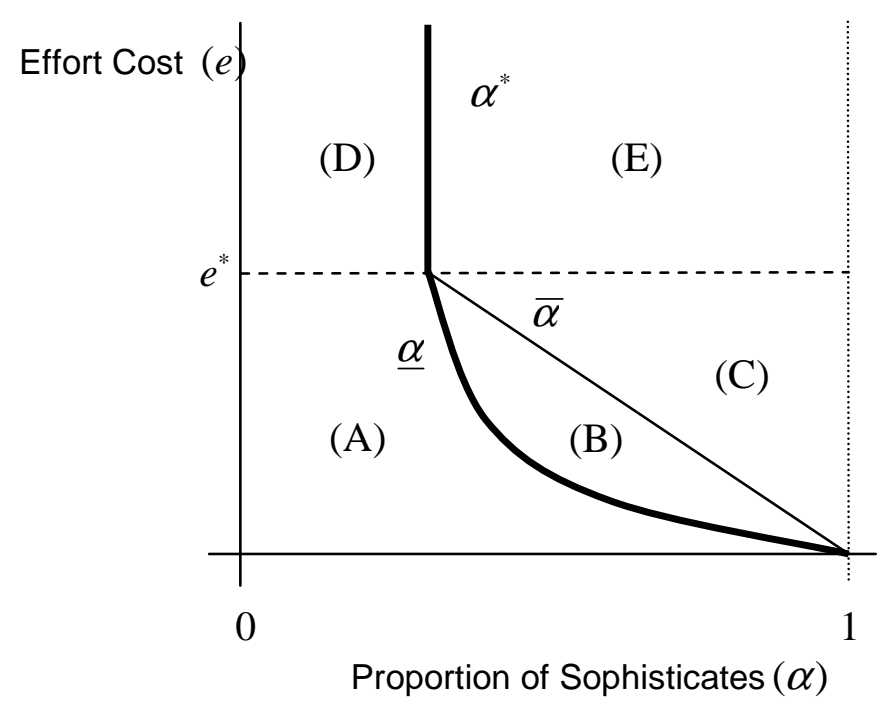

Note - In area (A) and (D) firm i sets $\mu_{i}=\{N\}$ and $p_{i}^{m}=v \forall$ i. In area (B), (C) and (E) firm 1 sets $\mu_{1}=\{T\}$ and firm $\mathrm{i} \neq 1$ sets $\mu_{i}=\{N\}$. In area (C) and (E) firm $\mathrm{i} \neq 1$ sets $p_{i}^{m}=v$ and firm 1 sets $p_{i}^{m}=v-\varepsilon$; in area (B) there is a mixed strategy equilibrium where firm 1 sets $p_{1}^{m} \in\left[\underline{p}, p^{*}\right)$ and firm $\mathrm{i} \neq 1$ sets $p_{i}^{m} \in\left[p^{*}, \bar{p}\right]$.

Figure 2 depicts the equilibrium conditions for finite number of firms for all levels of effort, $e$, and sophisticates, $\alpha$. Each area's letter (A, B, C, D and E) in the diagram relates to the corresponding equilibrium conditions in proposition 1. When there is a large proportion of naïve consumers relative to the effort cost (area A and D in Figure 2) all firms set non-transparent pricing strategies and (from similar intuition as the Bertrand paradox) set zero observable prices and from the Diamond paradox (1971) charge monopoly hidden fees. However, when there is a sufficient proportion of sophisticates (area B, C and E) there is an incentive for one firm to set a transparent strategy to attract sophisticates with lower market prices. ${ }^{9}$ It is only ever profitable for one firm to set a transparent strategy as competition for

\footnotetext{
${ }^{9}$ It does not attract naïve consumers as its observable (market) price is greater than non-transparent firms' observable prices.
} 
sophisticates brings zero profit compared to a positive profit supplying naïve consumers with non-transparent prices otherwise. ${ }^{10}$

In area $\mathrm{C}$ or $\mathrm{E}$ in Figure 2, it is unprofitable for a transparent firm to lower its price sufficiently to attract naïve consumers after they observe positive hidden fees: the firm simply prefers to supply sophisticates at a higher price. As such, in this situation transparent and non-transparent firms are not in direct competition for naïve consumers. Therefore, it follows that non-transparent firms continue to charge the monopoly hidden fees and a transparent firm sets its observable market price marginally lower.

However, when consumers face a low effort cost and there is a sufficient proportion of sophisticates for a firm to be transparent, and naïve consumers for the transparent firm to lower its price to attract them (area B), transparent and non-transparent firms are in direct competition for naïve consumers. In this situation firms face mixed incentives. Non-transparent firms wish to prevent their naïve consumers switching to a transparent firm, but also have an incentive to set high hidden fees to exploit their effort costs. The transparent firm has an incentive to marginally undercut non-transparent firms' lowest expected price and supply any sophisticates, but also has an incentive to lower its price further to attract naïve consumers, until the lower bound price, below which it is more profitable to supply any sophisticates at a higher price.

This intuition suggests that competition between transparent and nontransparent firms for naïve consumers is an important factor in defining the equilibria of this model. If there is limited incentive for a transparent firm to attract naïve consumers when they observe hidden fees then all consumers are worse off relative to a situation where it has a large incentive to attract naïve consumers, as the results in the following section describes.

\footnotetext{
${ }^{10}$ There may be more than one transparent firm in the market if firms have capacity constraints, because they will receive positive profit. However, when capacities are full, transparent firms would have no incentive to attract naïve consumers. Similarly, other solutions to the Bertrand paradox (product differentiation or switching costs) also introduce more than one transparent firm.
} 


\section{Comparative Static Results}

This section discusses the comparative static results of the model. In particular it describes the impact of changes in (a) the proportion of sophisticates; (b) the level of effort costs; and (c) the number of firms in the market. The changes are assumed to occur before stage 1. To consider changes in effort cost, $e$, and number of firms, $n$, it is useful to consider $e^{*}$ and $\alpha^{*}$ in terms of $n$ (denoted $n^{*}$ and $\tilde{n}$, respectively), $\bar{\alpha}$ in terms of $e$ (denoted $\bar{e}$ ), and $\underline{\alpha}$ in terms of $e$ and $n$ (denoted $\underline{e}$ and $\underline{n}$, respectively). In the following, define $\pi^{T}$ and $\pi^{N}$ as a transparent and non-transparent firm's profit, and expected producer and consumer surplus as $P S$ and $C S$, respectively. Producer surplus is the industry's expected profits and using the fact that consumers have unit demand and all are supplied, expected consumer surplus is calculated by subtracting producer surplus from the available surplus, $C S=v^{*}-P S .{ }^{11,12}$ The following analysis is restricted to a finite number of firms.

Result 1 If there is a small increase in $\alpha$ :

when $e<e^{*}$,

(i) if $\alpha<\underline{\alpha}$, there is no effect upon consumer surplus $(C S)$;

(ii) if $\underline{\alpha}<\alpha<\bar{\alpha}, C S$ decreases;

(iii) if $\alpha>\bar{\alpha}$, there is no effect upon $C S$;

(iv) if $\alpha$ becomes greater than $\underline{\alpha}$, such that it provides a firm to set $\mu_{1}=\{T\}, C S$ increases;

(v) if $\alpha$ becomes greater than $\bar{\alpha}, C S$ decreases; when $e>e^{*}$,

(vi) if $\alpha<\alpha^{*}$, there is no effect upon CS ;

\footnotetext{
${ }^{11}$ The simplifying demand assumptions mean that total welfare is fixed at $v^{*}$.

${ }^{12}$ Since switching (sometimes) occurs in equilibrium an alternative measure of consumer surplus could include the consumers' effort cost of switching firms; such that $C S=v^{*}-P S-e\left(1-\alpha^{\prime}\right)\left(1-F_{i}\left(p_{1}+e\right)\right.$. However, the signs of the comparative static results in this section remain unchanged under this alternative measure of consumer surplus. The only significant difference between the two measures is that when switching is observed in equilibrium total welfare (the sum of producer surplus and consumer surplus) is lower.
} 
(vii) if $\alpha>\alpha^{*}$, there is no effect upon CS ;

(viii) if $\alpha$ becomes greater than $\alpha^{*}$, it provides a firm to set $\mu_{1}=\{T\}$, but there is no effect upon $C S$.

\section{Proof See Appendix C}

In terms of Figure 2, increasing sophisticates can be seen as moving horizontally left to right. Result 1 suggests that moving the initial level out of area $A$ benefits consumers as it provides an incentive for a firm to set a transparent strategy to compete for naïve consumers. Any movement within areas $A$ and $D$ has no effect upon consumer surplus as firms set the monopoly price; whereas, any movement within areas $C$ and $E$, and from $D$ to $E$ has a near zero impact upon consumer surplus as a greater proportion of sophisticates who benefit from prices marginally lower than the monopoly level. If area $B$ is the initial position, increasing sophisticates reduces consumer surplus because it provides the transparent firm with less of an incentive to attract naïve consumers, which provides non-transparent firms and the transparent firm with a stochastically dominated first-order pricing distribution. Movement to area $C$ from $B$ decreases consumer surplus as prices rise since the transparent firm has no incentive to compete for naïve consumers. ${ }^{13}$

Result 2 If there is a small increase in $e$ :

when $e<e^{*}$,

(i) if $e<\underline{e}$, there is no effect upon consumer surplus $(C S)$;

(ii) if $\underline{e}<e<\bar{e}, C S$ decreases;

(iii) if $e>\bar{e}$, there is no effect upon CS ;

(iv) if $e$ becomes greater than $\underline{e}$, such that it provides a firm to set $\mu_{1}=\{T\}, C S$ increases;

\footnotetext{
${ }^{13} \mathrm{An}$ increase in $\alpha$ has a similar effect as increasing $\lambda$ because both increase the proportion of sophisticates within the model. In Figure 1, an increase in $\lambda$ shifts $\alpha^{*}$ and pivots $\underline{\alpha}$ and $\bar{\alpha}$ to the left, but $e^{*}$ remains unchanged. This reduces area $\mathrm{A}$ and $\mathrm{D}$, and squeezes area $\mathrm{B}$ as $\partial \bar{\alpha} / \partial \lambda>\partial \underline{\alpha} / \partial \lambda$, but area $\mathrm{C}$ and $\mathrm{E}$ increase in size. The impact of an increase in $\lambda$ is greater when $\lambda>\alpha$ but is not otherwise.
} 
(v) if e becomes greater than $\bar{e}, C S$ increases.

when $e>e^{*}$,

(iv) there is no effect upon CS ;

where $\underline{e}=v^{*} /[n \alpha(1-\lambda)]-v^{*} / n$ and $\bar{e}=v^{*}(1-\alpha)$.

\section{Proof See Appendix C}

A decrease in the effort cost can be seen as moving vertically downwards in Figure $2 .{ }^{14}$ This decreases area $\mathrm{B}$ as $\partial \underline{\alpha} / \partial e<0$, which increases area $\mathrm{A}$; the slope of $\bar{\alpha}$ remains constant and thus the size of other areas are constant. In and between areas $A$ and $D$, and areas $C$ and $E$, consumer surplus is unaffected by changes in effort cost as firms continue to charge monopoly and near monopoly prices, respectively. Moving into area $B$ from $C$ provides firms with an incentive to compete for naïve consumers, with increasing intensity as the effort cost falls. However, moving into area A from $B$ reduces consumer surplus as it eliminates the incentive for a firm to set a transparent strategy so firms set monopoly hidden fees. Result 3 compares the benefit of an increase in sophisticates and effort for transparent and non-transparent firms.

Result 3 A small increase in $\alpha$ increases a transparent firm's profit, but a non-transparent firm's profit falls or remains constant. That is,

$$
\frac{\partial \pi^{T}}{\partial \alpha}>0 \geq \frac{\partial \pi^{N}}{\partial \alpha}
$$

The increase in profit from a small increase in e experienced by the transparent firm is at least as big as a non-transparent firm's profit increase. That is,

$$
\frac{\partial \pi^{T}}{\partial e} \geq \frac{\partial \pi^{N}}{\partial e}>0 \quad \text { if } e<e^{*} \text { and } \underline{\alpha}<\alpha<\bar{\alpha}, \text { with equalities if not. }
$$

\footnotetext{
${ }^{14}$ Notice that an increase in $e$ is the same as a decrease in $v^{*}$ as it simply changes the ratio $e / v^{*}$, which is present in $\underline{\alpha}, \bar{\alpha}$ and $e^{*}$.
} 


\section{Proof See Appendix C}

An increase in sophisticates benefits a transparent firm (in area B) because, firstly, there are more sophisticates initially attracted by a lower observable market price thus sales increase; and secondly, prices are higher due to the lesser incentive to attract the smaller proportion of naïve consumers. Nontransparent firms lose some naïve consumers but are benefited by the higher prices to the extent that their profits remain constant. However, when nontransparent market prices reach the monopoly level and a transparent firm marginally undercuts (area $\mathrm{C}$ or $\mathrm{E}$ ) increasing sophisticates only benefits the transparent firm by increasing its sophisticated patronage. Since nontransparent firms cannot increase prices, their profits fall.

All firms benefit from an increase in effort cost (in area B) due to a reduction in price competition, but the transparent firm benefits most. At low levels of $e$, firms need the larger proportion of consumers to be sophisticated for there to be an incentive for a firm to set a transparent pricing strategy (see Figure 2), as prices will be low due to the naïve consumers' ease of switching firms. As effort increases a transparent firm has a smaller incentive to compete for naïve consumers, so prices rise with a transparent firm's pricing distribution rising more rapidly than non-transparent firms'.

Given all firms benefit from an increase in effort cost firms may have a collective incentive to raise them. ${ }^{15}$ This is an apparently paradoxical result as it might be thought that the transparent firm would prefer lower effort costs. In actual fact only the effort cost of switching to the transparent firm matters for prices (as long as effort costs to search other firms remain positive) as consumers only consider the cost of switching to the transparent firm. This suggests that, although effort cost is exogenous, there may be an incentive for the transparent firm to make it difficult for it to attract naïve consumers. Therefore, there is the potential for two types of obfuscation occurring: firstly,

\footnotetext{
${ }^{15}$ For a similar result see Wilson (2006) where it is shown that it may be more profitable for firms to collectively increase obfuscation strategies (search costs) rather than increasing product differentiation (switching costs).
} 
non-transparent firms fool naïve consumers with low observable prices and high hidden fees; secondly, a transparent firm has a paradoxical incentive to increase the complexity of the switching task for naïve consumers. ${ }^{16}$ In the terminology of Fudenberg and Tirole (1984) increasing effort cost is a puppy dog ploy as it dampens competition between firms.

If sophisticated consumers have no effort cost of searching the market, the equilibrium is identical to Stahl (1989) where sophisticates and naïve consumers are equivalent to 'shoppers' and 'captives', respectively. Firms have no incentive to set transparent prices as sophisticates will shop at the lowest priced firm regardless. Therefore, observable prices are zero and firms have a mixed incentive to set hidden fees high to exploit naïve consumers but low to attract sophisticates.

Result 4 If there is a small increase in $n$ :

when $n<n^{*}$,

(i) if $n$ becomes greater than $\tilde{n}$, it provides a firm to set $\mu_{1}=\{T\}$, but there is no effect upon consumer surplus $(C S)$;

when $n>n^{*}$,

(ii) if $n$ becomes greater than $\underline{n}$, such that it provides a firm to set $\mu_{1}=\{T\}, C S$ increases;

where $n^{*}=v^{*} /\left(v^{*}-e\right), \underline{n}=v^{*} /[e \alpha(1-\lambda)]-v^{*} / n$ and $\tilde{n}=1 /[\alpha+\lambda(1-\alpha)]$.

\section{Proof See Appendix C}

Increasing $n$ in Figure 2 shifts $e^{*}$ upwards, and the slope of $\bar{\alpha}$ remains constant, but $\underline{\alpha}$ and $\alpha^{*}$ pivots and shifts to the left, respectively, to the extent that $\underline{\alpha}=\bar{\alpha}=\alpha^{*}$ when $e=e^{*}$. This reduces the size of area $\mathrm{D}$, but increases area $\mathrm{B}$ and $\mathrm{C}$; the effect on area $\mathrm{A}$ and $\mathrm{E}$ depends upon the slope of $\underline{\alpha}$ and $\bar{\alpha}$, respectively. Result 4 suggests that increasing $n$ only benefits consumers

\footnotetext{
${ }^{16}$ Of course, a transparent firm may also have an incentive to reduce the effort cost for naïve consumers if rival firms are unaware of the change.
} 
if there is movement from A to B. Otherwise, increasing $n$ does not increase price competition between firms. Intuitively, firms prefer to conceal prices, where they enjoy an equal share of the naïve consumers' surplus, compared to vigorously competing with another transparent firm, in which they receive zero profit. Thus, non-transparent firms simply divide the available surplus from naïve consumers between more firms which reduces their share, whereas a transparent firm's profit remains unaffected. As such, consumers are not benefited. This is a similar result to Spiegler (2006a) who finds that firms increase obfuscation strategies when there are more competitors to counteract the more intense price competition.

\section{Policy Implications}

The model suggests firms have an incentive to exploit consumer naivety by obfuscating price information to lessen price competition to the detriment of consumer welfare. Regulating markets affected by consumer naivety is problematic, especially if firms' statements are essentially accurate. This section discusses three remedies that regulators may utilise if firms deliberately try to mislead consumers, whilst considering the implications of potential limitations of the model.

It could be argued that given a transparent firm has an incentive to warn consumers, a regulator may expect adverse effects from obfuscation to be short-term and therefore regulation is unnecessary. However, in a situation where firms interact over several periods firms may choose not to warn consumers when acting competitively. For instance, if consumers within the market in any one period are (randomly) drawn from a larger population and a firm is consistently transparent over several periods it may be more profitable in the long-term not to warn consumers, as prices fall to marginal cost when all naïve consumers become sophisticated.

Thus, if a regulator chooses to intervene in the market it firstly may decide to warn consumers of the potential of being misled to attempt to increase the 
number of sophisticates within the market. This model predicts the effect of such a remedy varies with the amount of sophisticates within the market. If there are very few sophisticates, increasing the sophisticated pool may provide an incentive for one firm to set a transparent strategy and compete for naïve consumers which would reduce prices. However, if increasing sophisticates actually dampens the competition for naïve consumers, prices could increase. Nevertheless, a regulator may have to assess the damage caused by high prices for a short period compared to intermediate prices for a longer period if firms interact repeatedly.

Secondly, a regulator could help consumers search and switch suppliers more effectively to reduce their effort cost. Again the success of such a policy depends upon the initial proportion of sophisticates and level of effort cost. If there is already competition between non-transparent firms and a transparent firm, reducing consumers' effort costs may increase competition. But below some threshold it would eliminate competition altogether as all firms would set non-transparent strategies and charge monopoly prices.

Finally, a regulatory body may force firms to set transparent strategies, as the European Commission has implemented in the European airline market. The model suggests that this would be the most effective policy as complete transparency will render consumers' naivety irrelevant and competitive forces reduce prices to marginal cost. Of course, the regulator must be certain that the conduct of the market is competitive as employing this policy in a market where a tacit understanding could exist may be detrimental to consumer welfare as increased price transparency may actually facilitate higher prices as it reduces the ability of secret price cuts, which undermines collusive understandings (Albæk et al, 1997).

\section{Conclusion}

Firms obfuscate product information in several markets despite intense price competition. This paper has considered whether profit-maximising firms have 
an incentive to obfuscate a component of their prices if there are a proportion of naïve consumers within the market. It has shown that the ability to make prices non-transparent but still attract naïve consumers limits price competition and allows firms to set prices above marginal cost. This result is found to be robust for markets that are susceptible to entry and markets where firms can simultaneously set transparency strategies with prices.

According to the model, the European Commission was correct to require airlines to set prices inclusive of TFCs because prices fall. Alternative policies of educating naïve consumers and reducing naïve consumers' effort to search the market could enable firms to set higher prices in some situations. Nevertheless, when firms interact repeatedly a regulator employing such remedies may have to assess the damaged cause by high prices for a short period compared to intermediate prices for a longer period.

The European Commission's intervention into the European short-haul market provides a natural experiment to analyse whether airlines were benefiting from less intense price competition due to firms' obfuscation strategies. The model suggests prices would be higher in the period before the intervention compared to prices after the intervention. This analysis may provide evidence that consumers were being exploited as the AUC feared and provide justification for the European Commission's intervention. 


\section{References}

Albæk, S, Møllgaard, P and Overgaard, P (1997) "Government-Assisted Oligopoly Coordination? A Concrete Case," Journal of Industrial Economics, 45(4), 429-443

AUC Report (2005) "Taxes, Fees and Charges: An AUC Report on Pricing on Airlines' Websites," available at: www.auc.org.uk

Bertini, M and Wathieu, L (2006) "The Framing Effect of Price Format," HBS Working Paper 06-055

Chen, Y, lyer, G and Pazgal, A (2002) "Limited Memory and Market Competition," mimeo, University of California at Berkeley

Cheong, I and Kim, J (2004) "Costly Information Disclosure in Oligopoly," Journal of Industrial Economics, 52 (1), 121-132

DellaVigna, S and Malmendier, U (2004) "Contract Design and Self-Control:

Theory and Evidence," Quarterly Journal of Economics, 119, 353-402

Eliaz, K and Spiegler, R (2006) "Contracting with Diversely Naïve Agents," Review of Economic Studies, 73(3), 689-714

Ellison, G (2005) "Bounded Rationality in Industrial Organisation," in Advances in Economics and Econometrics: Theory and Applications, Ninth World Congress, Cambridge: Cambridge University Press

Ellison, G and Ellison, S (2004) "Search, Obfuscation, and Price Elasticities on the Internet," MIT Department of Economics Working Paper 04-27

Gabaix, X and Laibson, D (2006) "Shrouded Attributes, Consumer Myopia, and Information Suppression in Competitive Markets," Quarterly Journal of Economics, 121 (2), 505-540

Garrod, L (2006) "Surcharing as a Facilitating Practice," CCP Working Paper 06-17

Gaudeul, A and Sugden, R (2007) "Spurious Complexity and Common Standards in Markets for Consumer Goods," CCP Working Paper 0720

Heidhues, P and Koszegi, B (2006) "Competition and Price Variation when Consumers are Loss Averse," WZB Discussion Paper SP II 2006-25

Hossain, T and Morgan, J (2006) "Shrouded Attributes and Information Suppression: Evidence from Field Experiments," mimeo, University of California, Berkeley 
Kahneman, D and Tversky A (1979), "Prospect Theory: An Analysis of Decisions Under Risk," Econometrica, 47, 263-91

Milgrom, P (1981) "Good News and Bad News: Representation Theorems and Applications," Bell Journal of Economics, 12(2), 380-391

Møllegaard, P and Overgaard, P (2005) "Information Exchange, Market Transparency and Dynamic Oligopoly," in Collins, W (eds) Issues in Competition Law and Policy

Piccione, M and Rubinstein, A (2003) "Modeling the Economic Interaction of Consumers with Diverse Abilities to Recognize Equilibrium Patterns," Journal of European Economic Association, 1, 212-223

Rotemberg, J (2005) "Customer Anger at Price Increases, Changes in the Frequency of Price Adjustment and Monetary Policy," Journal of Monetary Economics, 52, 829-52

Salop, S and Stiglitz, J (1977) "Bargains and Ripoffs: A Model of Monopolistically Competitive Price Dispersion," Review of Economic Studies, 44, 493-510

Spiegler, R (2006a) "Competition over Agents with Boundedly Rational Expectations," Theoretical Economics, 1, 207-231

Spiegler, R (2006b) "The Market for Quacks," Review of Economic Studies, 73(4), 1113-1131

Stahl, D (1989) "Oligopolistic Pricing with Sequential Consumer Search," American Economic Review, 79, 700-712

Thaler, R (1985) "Mental Accounting and Consumer Choice," Marketing Science, 4, 199-214

Wilson, C and Waddams Price, C (2007) "Do Consumers Switch to the Best Supplier?" CCP Working Paper 07-6 


\section{Appendices}

This appendix provides the proof of proposition 1, the necessary conditions for $F_{1}\left(\hat{p}_{i}-e\right)=1-F_{i}\left(p_{1}+e\right)$ and proofs of results 1-4.

\section{Appendix A: Proof of Proposition 1}

The proof of proposition 1 consists of two lemmata. Lemma 1 finds firms' optimal pricing strategies in stage 2 given $\alpha^{\prime}, e, M=\left\{\mu_{1}, \cdots, \mu_{n}\right\}$ and $W=\left\{\omega_{1}, \cdots, \omega_{n}\right\}$. Recall $\alpha^{\prime}=\alpha+\lambda(1-\alpha)$ if at least one firm sets $\omega_{i}=\{w a r n\}$ but $\alpha^{\prime}=\alpha$ otherwise. Lemma 2 finds firms' optimal transparency and warning strategies in stage 1 given optimal prices in stage 2. Define $\hat{n}$ and $n-\hat{n}$ as the number of non-transparent and transparent firms in the market, respectively. Denote firm $j$ as a firm that sets $\mu_{j}=\{T\}$ and all other firms $\mathrm{i} \neq \mathrm{j}$ set $\mu_{i}=\{N\}$. Define $\pi^{T}$ and $\pi^{N}$ as a transparent and non-transparent firm's profit, respectively.

Lemma 1 For given $\alpha^{\prime}$, $e$, and vectors $W$ and $M$, firms' optimal prices and profit are given below for the following situations.

(i) when $\hat{n}=0$

$$
\begin{aligned}
& p=c \\
& \pi^{T}=0
\end{aligned}
$$

(ii) when $1 \leq \hat{n}<n-1$

$$
\begin{array}{ll}
p_{j}=c & p_{i}=0 \text { and } \hat{p}_{i}=\min \{v, c+e\} \\
\pi^{T}=0 & \pi^{N}=\left(\hat{p}_{i}-c\right)\left(1-\alpha^{\prime}\right) / \hat{n}
\end{array}
$$

(iii) when $\hat{n}=n-1$

$$
\begin{array}{rr}
\text { if } \alpha^{\prime}<1-e / v^{*}, \quad p_{1} \in\left[\underline{p}, p^{*}\right) & p_{i}=0 \text { and } \hat{p}_{i} \in\left[p^{*}, \bar{p}\right] \\
\pi^{T}=e \alpha^{\prime} /\left(1-\alpha^{\prime}\right) & \pi^{N} \approx e /(n-1) \\
\text { if } \alpha^{\prime} \geq 1-e / v^{*}, \quad p_{1} \approx v & p_{i}=0 \text { and } \hat{p}_{i}=v \\
\pi^{T} \approx \alpha^{\prime} v^{*} & \pi^{N}=v^{*}\left(1-\alpha^{\prime}\right) /(n-1)
\end{array}
$$


(iv) when $\hat{n}=n$

$$
\begin{array}{r}
p=0 \text { and } \hat{p}=v \\
\pi^{N}=v^{*} / n \\
\text { where } p^{*} \approx e /(1-\alpha)+c, \underline{p}=p^{*}-e \text { and } \bar{p} \approx \min \left\{p^{*}+e, v\right\} \text {. }
\end{array}
$$

Proof To find firms' optimal pricing for all situations, this proof considers the cases where (i) all firms set transparent prices; (ii) when there are at least two transparent firms and at least one non-transparent firm; (iii) when there is only one transparent firm; and (iv) when all firms set non-transparent prices.

\section{(i) All Firms Transparent}

From the Bertrand paradox, it is optimal for firms to set $p=c$ and receive $\pi^{T}=0$.

\section{(ii) At Least Two Transparent and One or More Non-Transparent Firms}

Initially assume (to be proven below) that sophisticates are optimally attracted to transparent firms. Transparent firms compete for sophisticates so set $p_{j}=c$ and expect to share them equally. Thus, they receive $\pi^{T}=0$. However, non-transparent firms can ensure the trade of naïve consumers by setting observable prices below $p_{j}=c$, given they can set $\hat{p}_{i}>0$. When there are two non-transparent firms competition forces them to set $p_{i}=0$ and thus naïve consumers are equally distributed (in expectation) among nontransparent firms. When there is only one non-transparent firm, it is indifferent between setting $p_{i} \in[0, c) .{ }^{17}$

\footnotetext{
${ }^{17}$ Henceforth, to simplify the analysis it is assumed that there are at least two non-transparent firms in the market, but this makes no significant difference to proposition 1.
} 
Non-transparent firms have an incentive to exploit naïve consumers by setting high hidden fees. However, naïve consumers become sophisticated when they observe $\hat{p}_{x}>0$ and switch to the lowest-priced transparent firm if $\min \left\{P^{m}\right\}+e<\hat{p}_{x}$. It is not optimal for a non-transparent firm to allow naïve consumers to switch firms, so they set $\hat{p}_{i}=\min \left\{r^{*}, v\right\}=p_{i}^{m}$ where $r^{*}=\min \left\{P^{m}\right\}+e$ is naïve consumers' reservation price, which given transparent firms' prices is $r^{*}=c+e$. A lower price does not attract more naïve consumers as they are attracted by $p_{i}=0$ and it is not profitable for firms to attempt to attract sophisticates with $\hat{p}_{i}<c$ as they would make a loss even if sophisticates decide to visit non-transparent firms. Thus, non-transparent firms' profits are $\pi^{N}=(\min \{v, c+e\}-c)\left(1-\alpha^{\prime}\right) / \hat{n}$.

Thus, given $\hat{p}_{i}>p_{j}$, sophisticates will be attracted to transparent firms, as they correctly ex ante expect non-transparent market prices to be higher.

\section{(iii) One Transparent Firm}

As above, we initially assume (to be proven below) that sophisticates are attracted to the lower-priced transparent firm (firm 1). Again, it is optimal for non-transparent firms $(\hat{n}=n-1)$ to set $p_{i}=0 \forall \mathrm{i} \neq 1$, so each initially attracts $\left(1-\alpha^{\prime}\right) /(n-1)$ naïve consumers, but they will switch if $p_{1}+e<\hat{p}_{i}$. The proof of this section depends upon firm 1's incentive to attract naïve consumers after they observe $\hat{p}_{i}>0$. Assuming sophisticates are attracted to firm 1, the proof firstly considers firms' optimal (mixed strategy) pricing when it is feasible for firm 1 to attract sophisticates and proves that firm 1's prices are lower than firm i's $\forall i \neq 1$. Secondly, it then finds conditions where this pricing is optimal. Thirdly, it considers firms' optimal (pure strategy) pricing when it is not feasible for firm 1 to attract naïve consumers; again it is proven that firm 1's price is lower than firm i's $\forall \mathrm{i} \neq 1$. Finally, it is shown that non-transparent firms cannot 
deviate from the equilibrium by setting lower prices to initially attract sophisticates.

So to begin, initially assume firm 1 has an incentive to attract naïve consumers and all non-transparent firms set some $\hat{p}$. Firm 1 has two strategies. Firstly, it can set $p_{i}=\hat{p}-\varepsilon$ such that it marginally undercuts $\hat{p}$ to attract all sophisticates; ${ }^{18}$ secondly, it might lower its price further to $p_{1}=\hat{p}_{i}-e-\varepsilon$ to attract naïve consumers when they observe $\hat{p}_{i}>0$.

It is not optimal for non-transparent firms to allow their consumers to switch, so they have an incentive to set a common low market price, $\hat{p}=p^{*}$, which is the highest price such that firm 1 optimally sets $p_{1}=p^{*}-\varepsilon$ and does not attempt to attract naïve consumers. The price $p^{*}$ can be calculated by considering the profitability of firm 1's two strategies. Firstly, when firm 1 marginally undercuts $\hat{p}$ it receives:

$$
\pi_{1}=\alpha^{\prime}(\hat{p}-c-\varepsilon) \text {. }
$$

Secondly, when it lowers its price further to attract naïve consumers it receives:

$$
\pi_{1}=(\hat{p}-c-e-\varepsilon)
$$

The profit in (1) is greater than or equal to the profit in (2) for all $\hat{p} \leq e /(1-\alpha)+c+\varepsilon$. Thus, by definition $p^{*}=e /\left(1-\alpha^{\prime}\right)+c+\varepsilon$. However, this is not a pure strategy equilibrium because, if $p_{1}=p^{*}-\varepsilon$, non-transparent firms have an incentive to set $\bar{p}=\min \left\{p^{*}+e-\varepsilon, v\right\}$ to fully exploit the naïve consumers' effort to switch firms. But since $\bar{p}>p^{*}$, this provides firm 1 with an

\footnotetext{
${ }^{18}$ Recall sophisticates form equilibrium beliefs such that $E\left(\hat{p}_{i}\right)=\hat{p}_{i}$, so firm 1 cannot set $p_{1} \geq \hat{p}_{i}$ and attract them. If $p_{1}>\hat{p}_{i}$, sophisticates will randomly select a non-transparent firm, so firm 1 receives zero profit; if $p_{1}=\hat{p}_{i}$, sophisticates randomly select between all firms, which unambiguously reduces firm 1's profit compared to when it sets $p_{1}=\hat{p}_{i}-\varepsilon$ and attracts all sophisticates.
} 
incentive to reduce its price $p_{1}<p^{*}$ to attract naïve consumers; ${ }^{19}$ which provides non-transparent firms with an incentive to lower their price slightly, thus firm 1 has an incentive to lower its price, and so on. This occurs until non-transparent firms set $p^{*}$, in which case firm 1 marginally undercuts and begins the cycle again. Notice that the lowest price firm 1 sets is $\underline{p}=p^{*}-e$, as this is the (highest) price that attracts naïve consumers when nontransparent firms set a price marginally greater than $p^{*}$.

Thus, to begin the solution for the mixed strategy, consider firms' expected profit given their pricing distributions. If firm 1 sets a pricing distribution $F_{1}\left(\hat{p}_{i}-e\right)$, the expected profit of firm $\mathrm{i} \neq 1$ with $p_{i}=0$ and $\hat{p}_{i}>0$ is:

$$
E \pi_{i}=\left(\hat{p}_{i}-c\right) \frac{\left(1-\alpha^{\prime}\right)}{n-1}\left[1-F_{1}\left(\hat{p}_{i}-e\right)\right] .
$$

Firm i initially attracts $\left(1-\alpha^{\prime}\right) /(n-1)$ naïve consumers with $p_{i}=0$, but sets $\hat{p}_{i} \in\left[p^{*}, \bar{p}\right]$ such that it has a $1-F_{1}\left(\hat{p}_{i}-e\right)$ probability that $p_{1}>\hat{p}_{i}-e$ (in other words $\hat{p}_{i}<p_{1}+e$ ) where its consumers will not switch to firm 1 .

Given firm $\mathrm{i} \forall \mathrm{i} \neq 1$ sets a pricing distribution $F_{i}\left(p_{1}+e\right)$, the expected profit of firm 1 with market price, $p_{1}$, is:

$$
E \pi_{1}=\left(p_{1}-c\right)\left[\alpha^{\prime}+(n-1) \frac{\left(1-\alpha^{\prime}\right)}{n-1}\left[1-F_{i}\left(p_{1}+e\right)\right]\right]
$$

where (as long as $p_{1}<\hat{p}_{i} \forall \mathrm{i} \neq 1$ ) firm 1 can guarantee selling its product to sophisticates, $\alpha^{\prime}$. In addition, it attracts firm i's $\left(1-\alpha^{\prime}\right) /(n-1)$ naïve consumers if $p_{1}+e<\hat{p}_{i}$ which occurs with probability $1-F_{i}\left(p_{1}+e\right)$. It has this probability of attracting naïve consumers for each of the $(n-1)$ firms.

\footnotetext{
${ }^{19}$ Firm 1 could increase its price to $p_{1}=\bar{p}-\mathcal{E}$, but, from above, it is more profitable to attract naïve consumers $\forall \hat{p}>p^{*}$.
} 
Firms' equilibrium pricing distributions are now found. Firm i can set $p^{*}$ and supply its naïve consumers with certainty. Firm 1 can set $p_{1}=p^{*}-\varepsilon$ and supply its sophisticates with certainty and has zero probability of attracting naïve consumers. Thus, in equilibrium firms' pricing distributions are equal to the profits firms receive in this situation. When non-transparent firms set $p^{*}$ and firm 1 marginally undercuts, they receive:

$$
E \pi_{i}=\left[e+\varepsilon\left(1-\alpha^{\prime}\right)\right] /(n-1) \approx e /(n-1)
$$

and

$$
E \pi_{1}=e \alpha^{\prime} /\left(1-\alpha^{\prime}\right)
$$

respectively.

Equating the expected profit of firm $i$ in (3) and the profit it gains from selling to naïve consumers with certainty in (5) solves for firm 1's pricing distribution:

$$
F_{1}\left(\hat{p}_{i}-e\right)=1-\frac{e}{\left(\hat{p}_{i}-c\right)\left(1-\alpha^{\prime}\right)} .
$$

The pricing upper bound of firm i's distribution is $\bar{p}=\min \left\{v, p^{*}+e\right\}$ where $p^{*}+e \approx e\left(2-\alpha^{\prime}\right) /\left(1-\alpha^{\prime}\right)+c$. Since at $\bar{p}, F_{1}\left(\hat{p}_{i}-e\right)=(2-\alpha) /(1-\alpha)<1$, there is a mass at $\bar{p}$.

Equating the expected profit of firm 1 in (4) and the profit it gains from selling to sophisticates with zero probability of attracting naïve consumers given in (6) solves for the firm i's pricing distribution:

$$
F_{i}\left(p_{1}+e\right)=\frac{1}{1-\alpha^{\prime}}\left[1-\frac{e \alpha^{\prime}}{\left(p_{1}-c\right)\left(1-\alpha^{\prime}\right)}\right]
$$


To prove $\underline{p}=p^{*}-e$ consider $F_{i}\left(p_{1}+e\right) \rightarrow 0$ where the probability that it attracts naïve consumers tends to certainty. Thus, $\underline{p}=\alpha e /(1-\alpha)+c$, which as we expected is $p=p^{*}-e$. Appendix B shows the necessary conditions for $F_{i}\left(p_{1}+e\right)=1-F_{1}\left(\hat{p}_{i}-e\right)$.

Thus, for $F_{i}\left(p_{1}+e\right)$ non-transparent firms' expected profit is $E \pi_{i} \approx e /(n-1)$ $\forall \hat{p}_{i} \in\left[p^{*}, \bar{p}\right]$ but is less than otherwise. Similarly, for $F_{1}\left(\hat{p}_{i}-e\right)$ firm 1's expected profit is $E \pi_{1}=e \alpha^{\prime} /\left(1-\alpha^{\prime}\right) \forall p_{1} \in\left[\underline{p}, p^{*}\right)$ but less than otherwise. Given that it is optimal for firm 1 to set $p_{1} \in\left[\underline{p}, p^{*}\right)$ and non-transparent firms set $\hat{p}_{i} \in\left[p^{*}, \bar{p}\right]$ it follows that sophisticates are attracted to firm 1 , if nontransparent firms do not have an incentive to deviate (proved below).

We now consider under what parameters firm 1 has an incentive to attract naïve consumers from non-transparent firms, where the mixed strategy equilibrium only applies. Firm 1 does not have an incentive to attract naïve consumers when $p^{*} \geq v$, as it is not optimal for non-transparent firms to set higher prices when firm 1 marginally undercuts. Thus, setting $p^{*}=v$ and rearranging shows that it will never be optimal for firm 1 to attract naïve consumers if

$$
\alpha^{\prime} \geq 1-e / v^{*}
$$

Hence, when $\alpha^{\prime}<1-e / v^{*}$, optimal pricing is defined by the mixed strategy above, but when $\alpha^{\prime} \geq 1-e / v^{*}$ it is optimal for non-transparent firms to set $\hat{p}_{i}=v$, and for firm 1 to marginally undercut. Thus, when $\alpha^{\prime} \geq 1-e / v^{*}$ transparent and non-transparent firms receive

$$
\pi_{1}=\alpha\left(v^{*}-\varepsilon\right) \approx \alpha v^{*}
$$

and

$$
\pi_{i}=v^{*}\left(1-\alpha^{\prime}\right) /(n-1)
$$


respectively. Notice that firm 1 is again the lowest priced firm, so sophisticates visit the firm if non-transparent firms do not have an incentive to deviate from the potential equilibrium.

To complete this section's proof finally consider whether a non-transparent firm i could deviate by setting an unobservable price lower than firm 1 to attract sophisticates in either the pure or mixed strategy equilibrium above. Assume that firm $i$ announces a communication stating that its price is lower than firm 1 and sophisticates should visit it instead. It is not possible for firm $i$ to attract sophisticates because they believe that this is simply cheap talk, as if they visit firm $i$ it has an incentive to exploit their effort cost of switching to firm 1 by charging higher prices. Therefore, it is always optimal for sophisticates to visit the transparent firm as they expect prices to be lower and non-transparent firms cannot convince them otherwise, as they would set higher prices than firm 1 if sophisticates were to visit.

\section{(iv) No Transparent Firms}

As before non-transparent firms compete for naïve consumers through observable prices, so set $p=0$ (dropping subscripts). Thus, naïve consumers randomly select between firms and are shared equally between them. All market prices are initially unobservable and so sophisticates also randomly select a firm. Sophisticates must search to find the best deal and will if $p_{x}^{m}>E\left(p_{i}\right)+e \forall \mathrm{i}$. Thus, from the Diamond paradox (1971), each firm will set a $\hat{p}=v$, as for any $\hat{p}<v$ firms can always increase profit by setting a higher price by an amount marginally less than $e$; and there is no incentive to compete for each other's consumers because firms can never stimulate search by setting a lower unobservable $\hat{p}$. Therefore, sophisticates expect firms to set symmetric prices (which re-enforces their decision not to search) and randomly select between firms. Thus, firms receive

$$
\pi^{N}=v^{*} / n,
$$


because when naïve consumers observe $\hat{p}_{i}>0$ and notice their initial beliefs of firms' market prices are incorrect, as above, they also expect each firm to set the same high hidden fee $\hat{p}=v$, thus realise searching other firms would be suboptimal.

Lemma 2 For finite $n$, it is never profitable for two of more firms to set transparent prices. A 'marginal' firm that believes it will be the only transparent firm will set a transparent strategy:

$$
\begin{array}{lll}
\text { when } \alpha^{\prime}<1-e / v^{*}, & \text { if } \quad \alpha^{\prime}>v^{*} /\left(v^{*}+e n\right) & \text { but not otherwise; } \\
\text { when } \alpha^{\prime}>1-e / v^{*}, & \text { if } \quad \alpha^{\prime}>1 / n & \text { but not otherwise. }
\end{array}
$$

When firm 1 sets $\mu_{1}=\{T\}$, it also sets $\omega_{1}=\{$ warn $\}$. Otherwise, firm $i$ has a weakly dominant strategy to set $\omega_{i}=\{$ not warn $\} \forall i$.

As $n \rightarrow \infty$, firms are indifferent between setting $\mu_{i}=\{T, N\}$.

Proof Firstly, it is never optimal for two or more firms to set transparent strategies for finite $n$ as transparent firms receive zero profit compared to a positive profit otherwise. Therefore, in equilibrium for finite $n$ there will either be one or no transparent firms in the market. When $n \rightarrow \infty$, however, all firms' profit $\pi \rightarrow 0$, so they are indifferent between non-transparent and transparent strategies.

Thus, for finite $n$ comparing the profit of setting a transparent and nontransparent strategy of a marginal firm that believes it will be the only transparent firm provides us with the necessary equilibrium conditions. ${ }^{20}$ First, consider the case when $\alpha^{\prime}>1-e / v^{*}$. Comparing the profit of the only transparent firm in the market in (10) to the profit a firm receives where all set

\footnotetext{
${ }^{20}$ This pure strategy is focussed upon rather than considering the mixed strategy where all firms will become 'firm 1' with some probability. This has no effect upon results.
} 
non-transparent prices in (11) shows that there is an incentive for it to set transparent strategy if and only if

$$
\alpha^{\prime}>1 / n
$$

It is optimal to set a non-transparent strategy otherwise. Notice that $1-e / v^{*}>1 / n$ when $e<v^{*}(n-1) / n \equiv e^{*}$. Thus, when $e<e^{*}$ firm 1 sets a transparent strategy $\forall 1-e / v^{*}<\alpha^{\prime}<1$. When $e>e^{*}$ firm 1 sets a transparent strategy if $\alpha^{\prime}>1 / n$ but sets a non-transparent pricing strategy if $1-e / v^{*}<\alpha^{\prime}<1 / n$.

Now consider the case when $\alpha^{\prime}<1-e / v^{*}$. Comparing the profit of the only transparent firm in the market in (6) to the profit where all firms set nontransparent prices in (11) shows that there is an incentive for it to set a transparent strategy if

$$
\alpha^{\prime}>v^{*} /\left(v^{*}+e n\right)
$$

but it is optimal to set a non-transparent strategy otherwise. Notice that $v^{*} /\left(v^{*}+e n\right)>1-e / v^{*}$ when $e>v^{*}(n-1) / n \equiv e^{*}$, and thus when $e>e^{*}$ it is optimal for firm 1 to set a non-transparent price for all $\alpha^{\prime}<1-e / v^{*}$. However, when $e<e^{*}$ it is optimal for firm 1 to set a transparent price when $v^{*} /\left(v^{*}+e n\right)<\alpha^{\prime}<1$ but set a non-transparent price when $0 \leq \alpha^{\prime}<v^{*} /\left(v^{*}+e n\right)$.

This provides the necessary equilibrium conditions. For instance, when $e<e^{*}$ all firms set non-transparent strategies if $0 \leq \alpha^{\prime}<v^{*} /\left(v^{*}+e n\right)$, but one firm will set a transparent strategy if $v^{*} /\left(v^{*}+e n\right)<\alpha^{\prime}<1$. Whereas when $e>e^{*}$ all firms set non-transparent prices if $0 \leq \alpha^{\prime}<1 / n$, but there will be one transparent firm in the market if $1 / n<\alpha^{\prime}<1$.

To complete the proof, consider whether any firms wish to set $\omega_{i}=\{$ warn $\}$. Notice $e^{*}$ is unaffected by $\alpha^{\prime}$, so it remains constant whether consumers are 
warned or not. First consider the case when $e>e^{*}$. When $\alpha^{\prime}<1 / n$ firms receive $\pi_{i}=v^{*} / n$, which is independent of $\alpha^{\prime}$ therefore they will be indifferent between warning consumers or not. However, when $1>\alpha^{\prime}>1 / n$ nontransparent firms receive $\pi_{i}=v^{*}\left(1-\alpha^{\prime}\right) /(n-1)$ where $\partial \pi_{i} / \partial \alpha^{\prime}<0$ so choose $\omega_{i}=\{$ not warn $\} \forall \mathrm{i} \neq 1$. In contrast, firm 1 receives $\pi_{1} \approx \alpha^{\prime} v^{*}$ and thus it sets $\omega_{1}=\{$ warn $\}$ since $\partial \pi_{1} / \partial \alpha^{\prime}>0$. Therefore, $\alpha^{\prime}=\alpha+\lambda(1-\alpha)$ which substituting into (12) gives

$$
\alpha>\frac{1-\lambda n}{n(1-\lambda)} \equiv \alpha^{*}
$$

Now consider the case when $e<e^{*}$. As above, when $\alpha^{\prime}<v^{*} /\left(v^{*}+e n\right)$ firms receive $\pi_{i}=v^{*} / n$, so are indifferent between warning consumers or not. When $v^{*} /\left(v^{*}+e n\right)<\alpha^{\prime}<1-e / v^{*}$ non-transparent firms earn $\pi^{N} \approx e /(n-1)$ which is independent of $\alpha^{\prime}$ therefore all firms will be indifferent between warning consumers or not; however, firm 1 receives $\pi_{1}=e \alpha^{\prime} /\left(1-\alpha^{\prime}\right)$ where $\partial \pi_{1} / \partial \alpha^{\prime}>0$, so firm 1 chooses $\omega_{1}=\{$ warn $\}$. Therefore, $\alpha^{\prime}=\alpha+\lambda(1-\alpha)$ which substituting into (9) gives

$$
\alpha>1-\frac{e}{v^{*}(1-\lambda)} \equiv \bar{\alpha}
$$

Similarly, if $1-e / v^{*}<\alpha^{\prime}<1$ non-transparent firms receive $\pi_{i}=v^{*}\left(1-\alpha^{\prime}\right) /(n-1)$ where $\partial \pi_{i} / \partial \alpha^{\prime}<0$ so they choose $\omega_{i}=\{$ notwarn $\}$. Nevertheless, the transparent firm receives $\pi^{T} \approx \alpha^{\prime} v^{*}$, so it is optimal to choose $\omega_{1}=\{w a r n\}$. Therefore, $\alpha^{\prime}=\alpha+\lambda(1-\alpha)$ which substituting into (12) gives:

$$
\alpha>\frac{v^{*}}{(1-\lambda)\left(v^{*}+e n\right)} \equiv \underline{\alpha} .
$$


Therefore, warning consumers decreases the critical value of the (exogenous) number of sophisticates needed for all firms to set non-transparent pricing strategies.

Appendix B: Necessary Conditions for $F_{1}\left(\hat{p}_{i}-e\right)=1-F_{i}\left(p_{1}+e\right)$

Take the probabilities in (7) and (8) from unity to get:

$$
\begin{aligned}
& 1-F_{1}\left(\hat{p}_{i}-e\right)=\frac{e}{\left(\hat{p}_{i}-c\right)\left(1-\alpha^{\prime}\right)} \\
& 1-F_{i}\left(p_{1}+e\right)=-\frac{\alpha}{\left(1-\alpha^{\prime}\right)}\left[1-\frac{e}{\left(p_{1}-c\right)\left(1-\alpha^{\prime}\right)}\right]
\end{aligned}
$$

To see $F_{1}\left(\hat{p}_{i}-e\right)=1-F_{i}\left(p_{1}+e\right)$ set (7) equal to (15) and simplify to give the necessary condition:

$$
\left(p_{1}-c\right)\left(1-\alpha^{\prime}\right)=\frac{e \alpha^{\prime}\left(\hat{p}_{i}-c\right)}{\left(\hat{p}_{i}-c-e\right)}
$$

Substitute (16) into (8)

$$
F_{i}\left(p_{1}+e\right)=\frac{e}{\left(\hat{p}_{i}-c\right)\left(1-\alpha^{\prime}\right)}
$$

Notice that (17) is equivalent to (14) so $F_{i}\left(p_{1}+e\right)=1-F_{1}\left(\hat{p}_{i}-e\right)$.

\section{Appendix C: Proofs of Results 1-4}

\section{Proof of Result 1}

When $e<e^{*}$,

(i) if $\alpha<\underline{\alpha}, \pi_{i}=v^{*} / n \forall \mathrm{i}$, thus $P S=v^{*}$ and $C S=0$. Therefore, $\partial C S / \partial \alpha=0$. 
(ii) if $\quad \underline{\alpha}<\alpha<\bar{\alpha} \quad, \quad \pi_{1}=e \alpha^{\prime} /\left(1-\alpha^{\prime}\right) \quad$ and $\quad \pi_{i} \approx e /(n-1) \forall \mathrm{i} \neq 1 \quad$, so $P S=e /\left(1-\alpha^{\prime}\right) \quad$ where $\quad \alpha^{\prime}=\alpha+\lambda(1-\alpha) \quad$. Thus $\partial C S / \partial \alpha=-e /\left[(1-\lambda)(1-\alpha)^{2}\right]<0 ;$

(iii) if $\alpha>\bar{\alpha}, \pi_{1} \approx \alpha^{\prime} v^{*}$ and $\pi_{i}=v^{*}\left(1-\alpha^{\prime}\right) /(n-1) \forall \mathrm{i} \neq 1$, thus $P S=v^{*}$ and $C S=\alpha \varepsilon \approx 0$. Therefore, $\partial C S / \partial \alpha=\varepsilon \approx 0$;

(iv) if $\alpha$ becomes greater than $\underline{\alpha}$, from (i) and (ii) $C S$ increases from $C S=0$ to $C S=v^{*}-e /((1-\lambda)(1-\alpha)) ;$

(v) if $\alpha$ becomes greater than $\bar{\alpha}$, from (ii) and (iii) $C S$ decreases from $C S=v^{*}-e /((1-\lambda)(1-\alpha))$ to $C S=\alpha \varepsilon \approx 0$.

When $e>e^{*}$,

(vi) if $\alpha<\alpha^{*}, \pi_{i}=v^{*} / n \forall \mathrm{i}$, thus $P S=v^{*}$ and $C S=0$. Therefore, $\partial C S / \partial \alpha=0$.

(vii) if $\alpha>\alpha^{*}, \pi_{1} \approx \alpha^{\prime} v^{*}$ and $\pi_{i}=v^{*}\left(1-\alpha^{\prime}\right) /(n-1) \forall \mathrm{i} \neq 1$, thus $P S=v^{*}$ and $C S=\alpha \varepsilon \approx 0$. Therefore, $\partial C S / \partial \alpha=\varepsilon \approx 0 ;$

(viii) if $\alpha$ becomes greater than $\alpha^{*}$, from (vi) and (vii) CS remains constant.

\section{Proof of Result 2}

When $e<e^{*}$,

(i) if $e<\underline{e}, \pi_{i}=v^{*} / n \forall \mathrm{i}$, thus $P S=v^{*}$ and $C S=0$. Therefore, $\partial C S / \partial e=0$;

(ii) if $\underline{e}<e<\bar{e}, \pi_{1}=e \alpha^{\prime} /\left(1-\alpha^{\prime}\right)$ and $\pi_{i} \approx e /(n-1) \forall \mathrm{i} \neq 1$, so $P S=e /\left(1-\alpha^{\prime}\right)$. Thus $\partial C S / \partial e=-1 /\left(1-\alpha^{\prime}\right)<0$;

(iii) if $e>\bar{e}, \pi_{1} \approx \alpha^{\prime} v^{*}$ and $\pi_{i}=v^{*}\left(1-\alpha^{\prime}\right) /(n-1) \forall \mathrm{i} \neq 1$, thus $P S=v^{*}$ and $C S=\alpha \varepsilon \approx 0$. Therefore, $\partial C S / \partial e=0 ;$

(iv) if $e$ becomes greater than $\underline{e}$, from (i) and (ii) $C S$ increases from $C S=0$ to $C S=v^{*}-e /\left(1-\alpha^{\prime}\right)$.

(v) if $e$ becomes greater than $\bar{e}$, (ii) and (iii) $C S$ decreases from $C S=v^{*}-e /\left(1-\alpha^{\prime}\right)$ to $C S=\alpha \varepsilon \approx 0$.

When $e>e^{*}$, 
(vi) if $\alpha<\alpha^{*}, \pi_{i}=v^{*} / n \forall \mathrm{i}$, thus $P S=v^{*}$ and $C S=0$. Therefore, $\partial C S / \partial e=0 ;$

(vii) if $\alpha>\alpha^{*}, \pi_{1} \approx \alpha^{\prime} v^{*}$ and $\pi_{i}=v^{*}\left(1-\alpha^{\prime}\right) /(n-1) \forall \mathrm{i} \neq 1$, thus $P S=v^{*}$ and $C S=\alpha \varepsilon \approx 0$. Therefore, $\partial C S / \partial e=0$.

\section{Proof of Result 3}

A transparent firm's profit always increases with sophisticates but a nontransparent firm's decreases or remains constant. For instance, from Lemma $1, \partial \pi^{T} / \partial \alpha>0 \forall e$ but if $e<e^{*}$ and $\alpha>\bar{\alpha}$, or $e>e^{*}$ and $\alpha>\alpha^{*}, \partial \pi^{N} / \partial \alpha<0$; otherwise $\partial \pi^{N} / \partial \alpha=0$.

Furthermore, if $e<e^{*}$ and $\alpha>\bar{\alpha}$, or if $e>e^{*}$ firms' profits are unaffected by $e$. Yet, when $e<e^{*} \quad$ and $\quad \underline{\alpha}<\alpha<\bar{\alpha} \quad, \quad \partial \pi^{N} / \partial e=1 /(n-1)>0 \quad$ and $\partial \pi^{T} / \partial e=\alpha^{\prime} /\left(1-\alpha^{\prime}\right)>0$. Comparing the two first-order differentials for $e$ shows that $\partial \pi^{T} / \partial e>\partial \pi^{N} / \partial e$ if $\alpha^{\prime}>1 / n$, which is true since $\alpha>\underline{\alpha}$ and $e<e^{*}$.

If an increase in $e$ introduces a transparent firm into the market its profit increase will be greater as they initially have the same profit and then the transparent firm's profit will be greater.

\section{Proof of Result 4}

When $n<n^{*}$,

(i) if $n<\tilde{n}, \pi_{i}=v^{*} / n \forall \mathrm{i}$, thus $P S=v^{*}$ and $C S=0$. If $n>\tilde{n}, \pi_{1} \approx \alpha^{\prime} v^{*}$ and $\pi_{i}=v^{*}\left(1-\alpha^{\prime}\right) /(n-1) \forall \mathrm{i} \neq 1$, thus $P S=v^{*}$ and $C S=\alpha \varepsilon \approx 0$. Thus if $n$ becomes greater than $\tilde{n}$, there is no effect upon $C S$;

When $n>n^{*}$, 
(ii) if $n<\underline{n}, \pi_{i}=v^{*} / n \forall \mathrm{i}$, thus $P S=v^{*}$ and $C S=0$. If $n>\bar{n}$, $P S=e /\left(1-\alpha^{\prime}\right)$. Thus if $n$ becomes greater than $\underline{n}, C S$ increases from $C S=0$ to $C S=v^{*}-e /\left(1-\alpha^{\prime}\right)$,

where $n^{*}=v^{*} /\left(v^{*}-e\right), \underline{n}=v^{*} /[e \alpha(1-\lambda)]-v^{*} / n$ and $\tilde{n}=1 /[\alpha+\lambda(1-\alpha)]$. 